\title{
Die Stifte sind gespitzt
}

_ Als ich mich vor Kurzem mit einer Freundin (auch Ergotherapeutin) über ihre Arbeit unterhielt, erzählte sie: „Ich hab grad einen süßen Fünfjährigen. Total knuffig. Und die Eltern bringen sich auch voll ein.“ Da wurde ich schon etwas wehmütig. Wie schön war es doch, selbst mit Kindern und mit erwachsenen Klienten zu arbeiten.

_ Vor sechs Jahren hängte ich die praktische Arbeit zugunsten der redaktionellen Arbeit an den Nagel. Statt mit Klienten arbeite ich nun mit Ergotherapeuten und anderen Fachleuten zusammen, um gemeinsam tolle Artikel auf den Weg zu bringen.

- Auch wenn mein Ergotherapeutinnen-Herz jedes Mal hüpft, wenn mir Freunde erzählen, was ihre Klienten alles erreicht haben - tauschen möchte ich zur Zeit nicht. Das redaktionelle Arbeiten macht einfach zu viel Spaß. Und die Nähe zur Praxis ist vorhanden: Wir haben uns auf die Fahnen geschrieben, möglichst viel Praxisnutzen aufs Papier zu bringen. Dafür spitzen wir monatlich unsere Stifte.

_ Ich denke, dass Sie auch in dieser Ausgabe Unterstützung für Ihren Berufsalltag finden. Lesen Sie, worauf man beim motorischen Schreibtraining achten sollte, wie man den Mini-Mental Status-Test durchführt oder wie das Marburger Konzentrationstraining abläuft.

Viel Spaß beim Blättern und Schmökern,

Ihre

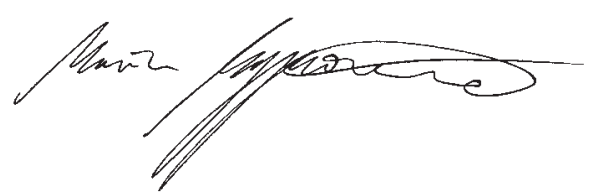

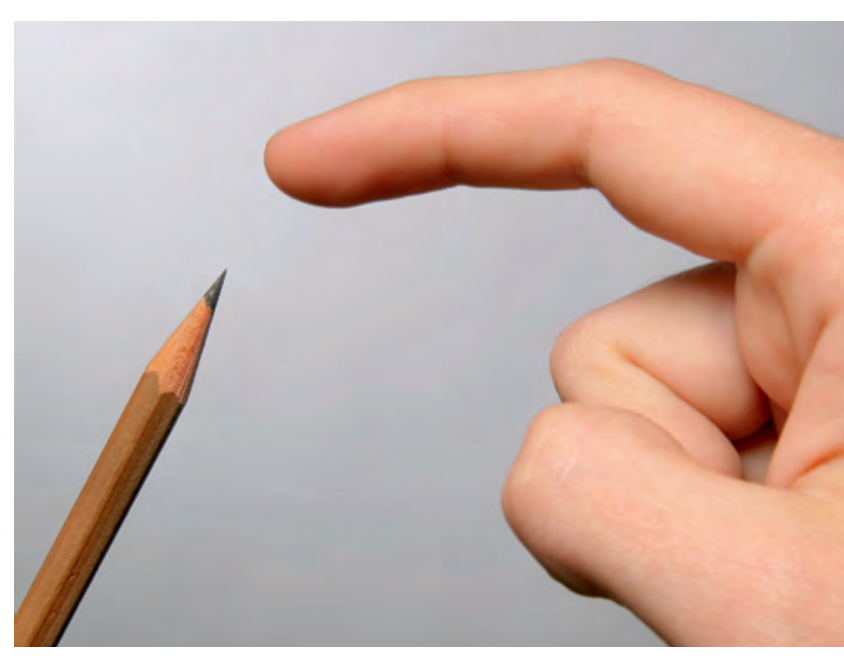

1 Teilnahme an der Einführungsveranstaltung für neue Wohnberatungskräfte

Bücher

2 Pakete mit je einem MKTManual für Kindergartenund Vorschulkinder sowie einem MKT-Programm

für Schulkinder

3 Ratgeber

„Diagnose Epilepsie“ 